\title{
Multi-stimuli Responsive Composite for heavy metal detection Based on Mesoporous Silica and Polyelectrolyte Brush
}

\author{
Long $\mathrm{Wu}^{1,2}$, Zan $G e^{1}$, Wei Li ${ }^{3}$,Feng Chen ${ }^{1,2, *}$, Zeping Zhou ${ }^{2, *}$ \\ ${ }^{1}$ Surfactants Key Enterprise Laboratory of Zhejiang Province, Zanyu Technology Group Co., LTD., \\ Hangzhou 310030, China \\ ${ }^{2}$ College of Materials Science and Engineering, Zhejiang University of Technology, Hangzhou \\ 310014, China \\ ${ }^{3}$ Nantong Acetic Acid Chemical Co., Ltd., Nantong 226009, China \\ "E-mail: chenf@zjut.edu.cn
}

doi: $10.20964 / 2020.01 .85$

Received: 17 July 2019 / Accepted: 21 November 2019 / Published: 30 November 2019

\begin{abstract}
Heavy metals are mostly non-degradable toxic substances, which are easy to be absorbed and enriched by organisms in the ecosystem, resulting in accumulation of the human body and difficult to be discharged. The electrochemical sensor is an effective method to detect heavy metal ions. Based on mesoporous silica, a multi-responsive block polymer brush PMAzo-PDMAEMA-SBA-15 was prepared by SI-RAFT method. Then the polymer brush was prepared into an electrochemical sensor to detect $\left[\mathrm{Fe}(\mathrm{CN})_{6}\right]^{3-}, \mathrm{Cu}^{2+}, \mathrm{Cd}^{2+}$ by $\mathrm{CV}$ test, and the detection limit is about $1.0 \times 10^{-7} \sim 2 \times 10^{-6} \mathrm{~mol} / \mathrm{L}$. It was found that the linear relationship between peak reduction current and metal ion concentration is excellent so the electrochemical sensors can be used for quantitative detection of ions. In addition, we also tested the performance of the sensor under the different environments such as $\mathrm{pH}$, temperature and ultraviolet light, and found that sensitivity and detection limit of the sensor would greatly increase at low $\mathrm{pH}$ and high temperature, and the UV-visible light could be used as the control switch of the sensor.
\end{abstract}

Keywords: Polyelectrolyte/mesoporous Silica, SI-RAFT, Environmental Response, Electrochemical Sensors, Metal Ions

\section{FULL TEXT}

(C) 2020 The Authors. Published by ESG (www.electrochemsci.org). This article is an open access article distributed under the terms and conditions of the Creative Commons Attribution license (http://creativecommons.org/licenses/by/4.0/). 